\title{
Oedema in the Lumbar Subcutaneous Fat, on Routine Magnetic Resonance Imaging, of Patients with No History of Cardiac, Renal or Hepatic Disease, Is Significantly Associated with Obesity and Age
}

WM West ${ }^{1}$, KP West ${ }^{2}$

\begin{abstract}
Objectives: To investigate the association between oedema in the subcutaneous fat of the lumbar region during routine magnetic resonance imaging (MRI) and patients' age, gender and body mass index (BMI).

Methods: One hundred and forty-nine consecutive examinations of 95 females and 54 males, 18 years and older, scanned at 1.5T between October 1, 2010, and December 31, 2010, were reviewed. Presence and extent of oedema were determined. Oedema was sized on the anatomical segments. Data were analysed using tests for means, odd's ratio (OR), Chi-squared test, McNemar's test, linear and backward stepwise multiple regression and analysis of variance (ANOVA).

Results: Patients with oedema had significantly higher BMI $\left(30.3 \mathrm{~kg} / \mathrm{m}^{2}\right.$ vs $\left.24.9 \mathrm{~kg} / \mathrm{m}^{2}, \mathrm{p}<0.001\right)$, and were older (49.9 years vs 43.9 years, $\mathrm{p}=0.01$ ) than those without oedema. The OR for oedema in obese vs non-obese patients was 8.6. The Chi-squared and McNemar tests were significant, $\mathrm{p}=0$ and $\mathrm{p}<$ 0.001 , respectively. Body mass index and age predicted oedema on backward stepwise regression and, on ANOVA, at 23.6\% and 4.7\%, respectively. Males were marginally less likely to have oedema ( $\mathrm{p}=$ $0.056)$ and had marginally less oedema $(\mathrm{p}=0.056)$ than females.

Conclusion: Body mass index and age, but not gender, predict oedema. Body mass index predicts oedema five times as much as age.
\end{abstract}

Keywords: Age, body mass index (BMI), lumbar, oedema, subcutaneous fat

WIMJ Open 2015; 2 (2): 86

\section{INTRODUCTION}

Oedema-like signal and fluid collections (for simplicity, the term "oedema" is used to apply to both entities for the remainder of the text) have been noted in the subcutaneous fat of the lumbar region on magnetic resonance imaging (MRI) during routine scans of patients who are not known, clinically, to have fluid overload, but little has been published on this entity.

Shi et al (1) reported that the amount of fluid present was associated with increasing body weight and increasing age. They speculated on the role that obesity may play in producing the oedema but did not evaluate the association with body mass index (BMI). Our search of the literature revealed no other publications on this issue.

From: ${ }^{1}$ Department of Surgery, Radiology, Anaesthesia and Intensive Care, The University of the West Indies, Kingston 7, Jamaica, West Indies and

${ }^{2}$ University of Roehampton, Whitelands College, London SW15 4JD, UK.

Correspondence: Dr WM West, Department of Surgery, Radiology, Anaesthesia and Intensive Care, The University of the West Indies, Kingston

7, Jamaica, West Indies. E-mail: wayne_west@hotmail.com
Cooper et al have previously demonstrated that sacral oedema which was not clinically detectable could be seen on computed tomography (CT) scan (2). Fluid prolongs the T2 relaxation of tissues on MRI, resulting in high signal on T2 weighted sequences. The high signal produced by fluid can be distinguished from that produced by fat by using fat saturation techniques. Fat saturation sequences are routinely used in MRI protocols as they are both sensitive and specific for the detection of fluid.

We sought to determine the associations between the presence and extent of oedema, measured with reference to anatomical structures, in the lumbar subcutaneous fat of a population of adults imaged with MRI, and patients' age, gender and BMI.

\section{SUBJECTS AND METHODS}

This is a retrospective review. The study was granted exemption from review by the Ethics Committee of our institution. 


\section{Patient population}

The computerized database of the MRI Unit at the University Hospital of the West Indies was reviewed for all patients 18 years and older who had MRI of the lumbar spine during the period October 12010 , to December 31, 2010. The images and patient data were retrieved. Patients were excluded if they had had recent back surgery or trauma, or a history of renal, cardiac or hepatic failure. This information was obtained on the day of the examination. Patients were also excluded if the image quality of the fat saturation (Fat Sat) examination was not satisfactory or if the Fat Sat sequence was not done.

\section{Imaging technique}

Imaging was performed on a 1.5T MR imaging unit (Signa; General Electric Medical Systems, Milwaukee, WI). The subcutaneous posterior lumbar soft-tissue oedema was evaluated on fat-saturated T2-weighted sagittal fast spinecho images. The MR imaging parameters were as follows: echo-train length, 8; TR range/TE range for sagittal T2weighted sequences, 3100-4000/80-90; TR/TE for sagittal T1-weighted sequences, 400/9. The following parameters were the same for all pulse sequences: section thickness, 4.0 $\mathrm{mm}$; intersection gap, $1.0 \mathrm{~mm}$; matrix, $512 \times 192$; and field of view, $30 \times 30 \mathrm{~cm}$.

\section{Image analysis}

The lumbar MR images were retrospectively reviewed by Wayne West (WW), consultant radiologist with 24 years of experience, for the presence and extent of oedema or fluid collections in the subcutaneous fat on the sagittal T2 Fat Sat sequence (Figure). Both oedema and fluid collections were measured relative to the anatomical structures over which the oedema and fluid collections extended. Lumbar oedema was

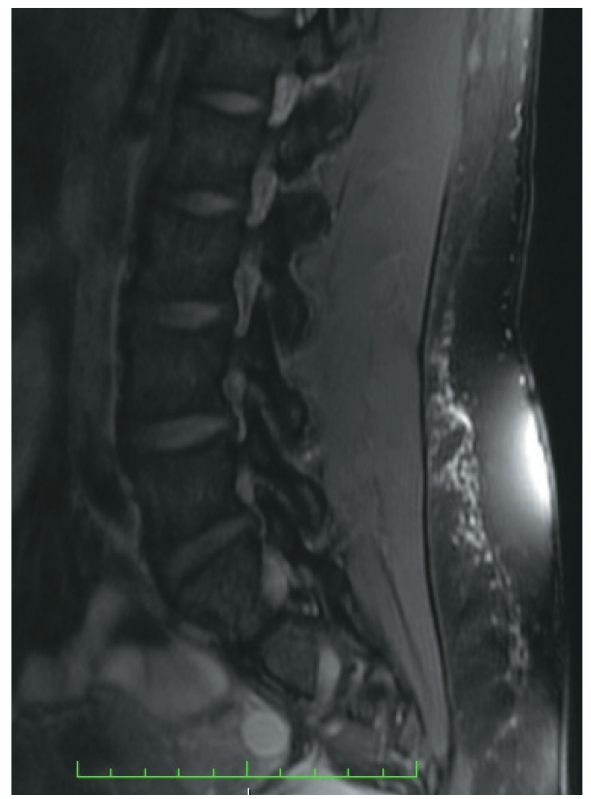

Figure: Oedema in the lumbar subcutaneous fat on T2 Fat Sat sequence. graded on a scale of $0-5$ according to length relative to the vertebral bodies on sagittal images.

0 : no oedema

1: equal to or less than the length of the related vertebra

2: more than one vertebra but equal to or less than the length of two related vertebrae and the intervertebral disc

3: more than two vertebrae and the inter-vertebral disc but equal to or less than the length of three related vertebrae and the two inter-vertebral discs

4: more than three vertebrae and the inter-vertebral discs but equal to or less than the length of four related vertebrae and the three inter-vertebral discs

5: Extending over the entire lumbar spine

When a patient had multiple foci of oedema, the sum of the lengths related to the vertebra was used to categorize the degree of oedema. Sacral oedema was graded on a scale of 0-3 using the length of the sacrum as a reference: $1 / 3$ or less was assigned a value of 1 , between $1 / 3$ and $2 / 3$ was assigned a value of 2 , and from $2 / 3$ to the entire length of the sacrum was assigned a value of 3 .

\section{Statistical analysis}

Data were analysed using StatPlus: mac 2009 and EPI Info Descriptive statistics; $t$-tests for means, odd's ratio (OR), Chi-squared test, McNemar's test, linear and backward stepwise multiple regression and analysis of variance (ANOVA) were done. A value of $p<0.05$ was considered statistically significant.

\section{RESULTS}

One hundred and sixty-nine examinations were performed on 65 males and 104 females. Twenty examinations on 11 males and nine females were excluded from the study. Of these, 11 patients, six females and five males, had acute back injury. Three patients, one male and two females, were excluded because of a history of renal failure. The Fat Sat examination was inadequate in three patients, two males and one female, and was not done in one male. One male was excluded because of a tumour involving the soft tissues of the back. The finding of oedema was equivocal in one male.

One hundred and forty-nine patients, 95 females (mean age 46.6 years) and 54 males (mean age 46.8 years), were included in the study. The difference in the means was not significant $(p=0.9)$. Sixty-eight patients, 50 females and 18 males, were positive for oedema in the lumbar subcutaneous tissue. Eighty-one patients, 45 females and 36 males, had no oedema.

The mean weight of patients without oedema was 72.8 $\mathrm{kg}$ and that of patients with oedema was $85.9 \mathrm{~kg}$; the difference in the means was significant $(p=0)$. Patients with oedema had significantly larger means for BMI $\left(30.3 \mathrm{~kg} / \mathrm{m}^{2}\right.$ vs $\left.24.9 \mathrm{~kg} / \mathrm{m}^{2}, p<0.001\right)$ and age (49.9 years vs 43.9 years, $p=0.01$ ) than patients without oedema (Table). Females had 
Table: Characteristics of patients with and without oedema in the subcutaneous fat of the lumbar region on magnetic resonance imaging

\begin{tabular}{lccc}
\hline Characteristics & $\begin{array}{c}\text { Patients with } \\
\text { oedema } \\
(\mathbf{n = 6 8 )}\end{array}$ & $\begin{array}{c}\text { Patients without } \\
\text { oedema } \\
(\mathbf{n = 8 1 )}\end{array}$ & $\boldsymbol{p}$ \\
\hline Age (mean), years & $49.9 \pm 13.6$ & $43.9 \pm 15.1$ & $p=0.01$ \\
Men, n (\%) & $18(12.1 \%)$ & $36(24.2 \%)$ & $p=0.056$ \\
Women, n (\%) & $50(33.6 \%)$ & $45(30.2 \%)$ & \\
BMI, Kg/m ${ }^{2}$ & $30.3 \pm 5.1$ & $24.9 \pm 3.7$ & $p<0.001$ \\
\hline
\end{tabular}

$\mathrm{BMI}=$ body mass index

significantly larger means for BMI $\left(28.1 \mathrm{~kg} / \mathrm{m}^{2}\right.$ vs $26.3 \mathrm{~kg}$ $/ \mathrm{m}^{2}, p=0.04$ ). The OR for oedema in obese (defined as BMI $\left.>30 \mathrm{~kg} / \mathrm{m}^{2}\right)$ vs non-obese patients was 8.6. The Chi-squared and McNemar tests were significant, $p=0$ and $p<0.001$, respectively. Compared to males, females had a marginally significant tendency both to have oedema $(p=0.056)$ and to have oedema extend over more anatomical segments $(2.4 \mathrm{vs}$ $1.5, p=0.056)$. On backward stepwise multiple regression, BMI and age were found to be significant independent variables predicting oedema.

\section{DISCUSSION}

The changes observed in the lumbar subcutaneous fat are due to extracellular fluid. The fluid may be in the form of oedema or small collections. These two patterns are unlikely to reflect different aetiologies but simply different amounts of fluid. The most likely cause of the extracellular fluid is fluid overload. Another consideration is microvascular dysfunction. In light of the possibility of microvascular dysfunction, we thought that it would be useful to determine the anatomical extent of the fluid as this may give some indication of the regional extent of the source of the findings. In both our population and in the study by Shi et al (1), being heavier and older predisposed to the presence of oedema in the soft tissues of the lumbar region on MR. Both studies indicate that gender per se is not a significant predictor of the presence of oedema. The studies differ in what was measured. Shi et al measured the volume of oedema. We measured the anatomical extent of the fluid. Our study adds that both the presence and extent of oedema, measured relative to anatomical structures, are significantly associated with BMI and not simply weight.

The mean BMI of $30.3 \mathrm{~kg} / \mathrm{m}^{2}$ for patients with oedema is indicative of obesity. The odds ratio (8.6) and McNemar test confirm this significant association of oedema with obesity. The importance of obesity in oedema is further highlighted by the fact that obesity predicted oedema five times as much as age $(23.7 \%$ vs $4.7 \%)$.

Older patients are more likely to have disease which would predispose to fluid overload. The low predictive association with increasing age suggests that senility is not a significant contributor to the phenomenon. Females are more likely to have oedema because of their significantly larger BMIs.

Obesity may predispose to oedema because it is associated with increased intra-abdominal pressure (2-5). Frezza et al have reported that "for every $1 \mathrm{~kg} / \mathrm{mm}(2)$ increase in BMI, there was on average a $0.07 \mathrm{mmHg}$ increase in opening pressure" (6), which in turn increases the pressure in the inferior vena cava $(7,8)$. The latter is likely to cause increase in the filtration in the interstitium because of increase in venous pressure. Obesity is also associated with expanded circulatory volume, which could result in increased intravascular pressure (9).

Further, obesity is associated with microvascular dysfunction. Tesauro and Cardillo reported that "obesity-related changes in vascular smooth muscle seem to disrupt the physiological facilitatory action of insulin on the responsiveness to vasodilator stimuli, whereas the adventitia and the perivascular fat appear to be a source of pro-inflammatory and vasoactive factors that may contribute to endothelial and smooth muscle cell dysfunction" (10). Other authors have reported on changes in the microvasculature in obesity (11).

Microvascular dysfunction may also occur in the absence of obesity. For example, Lu et al have reported that in the lung, "cigarette smoke increases endothelial cell permeability both in vitro and in vivo" (12). It would therefore be useful to determine the association between oedema in the lumbar fat and cigarette smoking.

Magnetic resonance imaging may thus detect oedema at an early stage before it becomes symptomatic, or oedema is able to be detected clinically in some patients. In others, MRI may detect evidence of microvascular dysfunction.

A possible clinical utility of reporting on the presence of oedema is that it may prompt the clinician to evaluate the patient for diseases other than that for which the patient was originally referred.

Thompson and Hakim have postulated that "regardless of the aetiology ... small vessel disease is a systemic condition with major healthcare consequences, requiring a new paradigm in the way we practice medicine" (13). Greenstein et al have reported on the association between cerebral microvascular damage in elderly, depressed patients with structural and functional abnormalities of subcutaneous small arteries. They found "profound abnormalities in both structure and function of small arteries, suggestive of deficiencies in local autoregulation" in biopsies of subcutaneous fat from the patient's gluteal region (14). This latter consideration should also inform research to determine if the finding may be a predictor of imminent cardiac or renal decompensation or reflect a degree of vascular dysfunction.

A possible limitation in this study is that cardiac, renal and hepatic disease, which could be causes of oedema, were excluded from the patients' histories rather than by clinical examination and laboratory investigation. Even with this consideration in mind, we believe that the results of the study are useful, as our objective was to study and report on 
patients who did not have a history of cardiac, hepatic and renal disease rather than those in whom such diseases were excluded.

Our study has demonstrated that oedema is significantly associated with obesity. Obesity in turn is well established to be significantly associated with cardiac and renal disease. Further research should, therefore, be undertaken to determine what percentage of patients with oedema do in fact have subclinical cardiac or renal disease.

In summary, we assessed the statistical association between age, weight, BMI and gender in adult patients with oedema in the subcutaneous fat of the lumbar region on MRI. Oedema was significantly associated with BMI and age but not gender. The model of BMI and age predicted $28 \%$ of oedema. Further research is needed to determine if the finding may have clinical utility in predicting early evidence of fluid overload or evidence of microvascular dysfunction.

\section{REFERENCES}

1. Shi H, Schweitzer ME, Carrino JA, Parker L. MR imaging of the lumbar spine: elation of posterior soft-tissue edema-like signal and body weight. Am J Roentgenol 2003; 180: 81-6.

2. Cooper M, Hacking JC, Dixon AK. Sacral edema: computed tomographic and anatomical observations. Clin Anat 1995; 8: 56-60.

3. Sugerman HJ, Windsor A, Bessos M, Wolfe L. Intra-abdominal pressure, sagittal abdominal diameter and obesity comorbidity. J Intern Med 1997; 241: 71-9.

4. Sugerman HJ, Windsor A, Bessos M, Kellum J, Reines H, DeMaria E. Effects of surgically induced weight loss on urinary bladder pressure, sagittal abdominal diameter and obesity co-morbidity. Int J Obes Relat Metab Disord 1998; 22: 230-5.

5. Lambert DM, Marceau S, Forse RA. Intra-abdominal pressure in the morbidly obese. Obes Surg 2005; 15: 1225-32.

6. Frezza EE, Shebani KO, Robertson J, Wachtel MS. Morbid obesity causes chronic increase of intraabdominal pressure. Dig Dis Sci 2007; 52: $1038-41$.
7. Ridings PC, Bloomfield GL, Blocher CR, Sugerman HJ. Cardiopulmonary effects of raised intrabdominal pressure before and after intravascular volume expansion. J Trauma 1995; 39: 1071-5.

8. Bloomfield G, Saggi B, Blocher C, Sugerman HJ. Physiologic effects of externally applied continuous negative abdominal pressure for intraabdominal hypertension. J Trauma 1999; 46: 1009 -14.

9. Lavie CJ, Messerli FH. Cardiovascular adaptation to obesity and hypertension. Chest 1986; 90: 275-9.

10. Tesauro M, Cardillo C. Obesity, blood vessels and metabolic syndrome. Acta Physiol (Oxf) 2011; 203: 279-86.

11. Valensi P, Smagghue O, Paries J, Velayoudon P, Lormeau B, Attali JR. Impairment of skin vasoconstrictive response to sympathetic activation in obese patients: influence of rheological disorders. Metabolism 2000; 49: $600-6$.

12. Lu Q, Sakhatskyy P, Grinnell K, Newton J, Ortiz M, Wang Y et al. Cigarette smoke causes lung vascular barrier dysfunction via oxidative stress-mediated inhibition of RhoA and focal adhesion kinase. Am J Physiol Lung Cell Mol Physiol 2011; 301: L847-57.

13. Thompson CS, Hakim AM. Living beyond our physiological means: small vessel disease of the brain is an expression of a systemic failure in arteriolar function: a unifying hypothesis. Stroke 2009; 40: e322-30.

14. Greenstein AS, Paranthaman R, Burns A, Jackson A, Malik RA, Baldwin RC et al. Cerebrovascular damage in late-life depression is associated with structural and functional abnormalities of subcutaneous small arteries. Hypertension 2010; 56: 734-40. doi: 10.1161/ HYPERTENSIONAHA.110.152801. Epub 2010 Aug 16.

Received 15 Oct 2014

Accepted 31 Oct 2014

Published 28 May 2015

Online: http://www.mona.uwi.edu/wimjopen/article/1630

(C) West and West 2015.

This is an open access article made freely available under Creative Commons Attribution 4.0 International (CC BY 4.0). Users are free to share, copy and adapt this work as long as the copyright holder (author) is appropriately and correctly credited. See http://creativecommons.org/ licences/by/4.0/deed.en_us for more information. 